\title{
Identifying Risk Factors of Breast Cancer Among Women Attending Selected Hospitals of Addis Ababa City: Hospital-Based Unmatched Case-Control Study
}

This article was published in the following Dove Press journal:

Breast Cancer: Targets and Therapy

\author{
Henock Duche' \\ Adino Tesfahun Tsegay (D) ${ }^{2}$ \\ Koku Sisay Tamirat $\mathbb{D}^{2}$ \\ 'Ethiopia Public Health Institute, Addis \\ Ababa, Ethiopia; ${ }^{2}$ Department of \\ Epidemiology and Biostatistics, Institute \\ of Public Health, College of Medicine and \\ Health Science, University of Gondar, \\ Gondar, Ethiopia
}

Background: Breast cancer, one of the chronic diseases, is the most common cancer among women in the world. In Ethiopia, late-stage breast cancer is widely diagnosed and women have very little access to adequate medication, pain relief, or palliative care. In addition, there are few research on risk factors for breast cancer in Ethiopia. A safer way out of this is to concentrate on prevention; one of the prevention methods is to recognize risk factors sooner. The study therefore aimed to establish risk factors for breast cancer among women in hospitals in the city of Addis Ababa.

Methods: Hospital-based, unmatched case-control research conducted in selected Addis Ababa hospitals from April to September 2017 (Case=110 and Control=110). Data were collected by standardized questionnaires for both cases and controls. Cases were initially detected by mammography screening accompanied by histopathological examinations, while controls were those women who were negative by mammogram testing, stress levels were assessed by perceived stress scale (PSS) and body mass index measured by WHO norm. Summary statistics Computed and binary logistic regression analysis to classify risk factors for breast cancer modified odds ratio (AOR) with 95\% confidence interval (CI) calculated. Results: The participants' mean age of was 43.80 years $(\mathrm{SD} \pm 12.63)$ and 39.64 years (SD \pm 12.91 ) for cases and controls, respectively. Physical activity (AOR $=0.2,95 \% \mathrm{CI}: 0.10,0.41$ ) was correlated with lower probability of breast cancer, while never breastfeed (AOR $=3.4,95 \%$ CI: $1.21,9.67)$; menopausal state (AOR $=6.8,95 \%$ CI: 1.92, 24.16), and body mass index above $25.1 \mathrm{~kg} / \mathrm{m}^{2}(\mathrm{AOR}=5.9,95 \% \mathrm{CI}: 2.16,16.48)$ were factors risk factors for breast cancer.

Conclusion: This research shows the importance of physical exercise, breastfeeding, menopausal status, and nutritional status in the occurrence of breast cancer. Actions aimed at increasing physical activity, breastfeeding habits and keeping a balanced diet will help to minimize the incidence of breast cancer.

Keywords: breast cancer, risk factors, case-control study, Ethiopia

\section{Background}

Breast cancer, one of the chronic diseases, is the most common cancer in women worldwide. It is one of the top three forms of cancer in terms of incidence and ranked among the top five in terms of mortality burden worldwide. In addition, female breast cancer is one of the world's leading forms in terms of number of new cases; an estimated 2.1 million diagnoses in 2018 contribute to $11.6 \%$ of the overall cancer incidence burden. ${ }^{1,2}$
Correspondence: Koku Sisay Tamirat Department of Epidemiology and Biostatistics, Institute of Public Health, College of Medicine and Health Science, University of Gondar, Ethiopia Email kokusisay23@gmail.com 
The occurrence rate is 94.2 new cases out of 100,000 in Australia/New Zealand and 29.9 new cases out of 100,000 in Easter Africa. Still, death rates are the opposite of 12.6 and 15.4 per 100,000, respectively 2. In Eastern Africa, cervical cancer has been the most widely diagnosed cancer for decades, but now there is a change to Breast Cancer, which is the most frequently diagnosed cancer in women with a lion share of $24.2 \%{ }^{2}$

There is no cancer registry system in Ethiopia; however, data from the collaboration project between the Addis Ababa City Cancer Registry and the African Cancer Registry Network (AFCRN) reported a total of 5701 cases of cancer between September 2011 and August 2014. Of these, 3820 (67\%) were female and 1881 (33\%) were male. The incidence rates for age groups were highest (38.4\%) for young age groups between 30 and 49 years of age. The most common cancer among females was breast cancer (33\%), followed by Cervix uteri $(17 \%)$ and Ovary (6\%) 4. Meanwhile, as the prevalence of breast cancer increased in women, the incidence of breast cancer also increased from 0.6 per 1000 screening tests in women aged 40 to 49 years. ${ }^{3}$ Meanwhile, as the age of women increased the incidence of breast cancer also increased from 0.6 per 1000 screening tests for women aged 40 to 49 years to 1.3 per 1000 screening tests for women aged 70 to 84 years. ${ }^{4}$

In low-and middle-income countries (LMICs), the facilities and services for regular mammography screening are often inaccessible and the health system is often conventional. In such lower resource settings, breast cancer is typically diagnosed at a late stage, and women have very little access to adequate medication, pain relief, or palliative care. Poorer prognosis in LMICs is associated with higher mortality rates relative to those in developing countries. To this end, a safer way out is to concentrate on prevention; one of the prevention methods is to recognize risk factors and to act on those that can be changed. ${ }^{5}$

Among the identified risk determinants of breast cancer include age, family history, medical history, weight, physical activity, alcohol consumption, cigarette smoking, breastfeeding, parity, menopausal status, stress, vegetable intake, fruit intake, and oral contraceptive use. ${ }^{6-12}$

No studies have been performed to analyze the risk factors for breast cancer in Ethiopia. The present study may add information on evidence of risk factors for breast cancer in Ethiopia and supporting evidence to reduce the burden of the disease. The results may also help to establish evidence-based approaches.

\section{Methods}

\section{Study Design, Period, and Setting}

An Institutional based unmatched case-control study was employed from April to September 2017. The study was conducted in four hospitals of Addis Ababa city administration namely, Tikur Anbessa Specialized Hospital, St. Paul's Hospital Millennium Medical College, Bethzatha Hospital, and Korean Hospital which provide cancer screening and treatment for the majority of the population. Moreover, the above-mentioned hospitals diagnose and treat breast cancer and are used as referral sites for the diagnosis and treatment of cancer. In addition, some of the treatment methods like radiation therapy only available in the capital city hospitals, and patients are referred from peripheral sites for better diagnosis and treatment.

\section{Population and Sample}

The study population includes all women present at the selected hospital in the data collection period. Cases were women who were above 15 years and newly diagnosed to have breast cancer were at the selected hospital. Controls were those women aged above 15 years who came for breast cancer screening and were found to negative and clinically ruled out by clinicians at the oncology department. In Ethiopia, more than $75 \%$ of breast cancer cases are treated in the capital city hospitals this could be due to service availability, accessibility and most of the medical practitioners are living and working in the capital.

The sample size determined by using double population proportion with the assumption of $80 \%$ power, $1: 1$ case to control ratio, $95 \% \mathrm{CI}$ and proportion of breast cancer among the unexposed group were $13 \%$ with a crude odds ratio of 2.03 and $10 \%$ non-response rate of the final sample size 220. ${ }^{13}$ All hospitals in Addis Ababa, which give breast cancer diagnostic and treatment centers with mammographic instruments were included in the study. By using the previous year's data of Addis Ababa Cancer Registry, the proportional allocation was made to each of the hospitals. Thus from Tikur Anbessa Specialized Hospital (55 cases and 55 controls), St. Paul's Hospital Millennium Medical College (40 cases and 40controls), Bethzatha Hospital (11 cases and 11 controls, and Korean Hospital (4 cases and 4 controls) were selected. Initially, cases or women who were diagnosed to have breast cancer were identified. Whereas women who came for breast cancer screening and were found to be negative by breast mammography were considered as controls. During the data collection period (April to September, 
2017), all breast cancer patients and controls were included in the sample until the total sample size was achieved.

Screening tests like mammography has paramount importance to detect breast cancer for early identification and prompt treatment of cancer before progress to advanced stages. For specific study cases were those women came hospital for mammography screening and confirmed by pathological examination of biopsy after mammography suggestions. Whereas, those women who screened to have negative mammography test and with additional rule out criteria's used by physicians were considered as Controls. Cases were selected during those women who had follow up and screening during our data collection time that was from April to September 2017.

\section{Data Collection Methods and Procedures}

The method of data collection for this study was an interview of study participants and a medical document review for crosschecking and for harvesting additional clinical information. Data was collected by using structured questionnaires for cases and controls that developed after assessing different literature with a similar context of the study. The data collection tool was initially developed in English and translated to the local language Amharic to keep its consistencies. Three data collectors and one supervisor were recruited and one-day training was given on how to make face-to-face interviewing of patients. For both cases and controls, interviews made at the selected hospitals about the socio-demographic, behavioral, clinical, and reproductive histories with the same checklists. Data about socio-demographic (age, residence, marital status, wealth status, and level of education), behavioral (smoking, BMI, alcohol drinking, and physical activity), and reproductive characteristics (parity, OC use, menopausal status, breastfeeding practices) was collected from the patient's interview and document review. The data collection tools adopted from previous studies, pretests were also done out and necessary corrections were made before the actual data collection process. ${ }^{6,8,12,14-16}$

- Case: abnormal histopathological changes confirmed by biopsy tests taken from the affected breast.

- Controls were breast cancer-free women negative by mammography and clinical examinations at the oncology department of the settings.

- Physical activity: Physical activity of 150 minutes and $<150$ minutes per week were defined as high and low. ${ }^{17}$
- Stress: measured by the Perceived Stress Scale (PSS) with 10 items having four scales with summarized scores ranged from 0 to 40 Thus, those women who scored PSS of 0-13 low stress, 14-26 moderate stress, and $27-40$ as high stress. ${ }^{15}$

- Fruit intake eating 2.5 servings of fruit in a day,

- Vegetable intake: Eating 2.5 grams of servings of vegetable in a day,

- Breast cancer in 1st-degree relative: breast cancer history in the family,

- Breast cancer in 2nd-degree relative: breast cancer history in the women close blood relative,

- Passive smokers: whoever had a family or co-worker who smokes a cigarette in their presence in close distance,

- Active smokers: who are current users of tobacco products, such as cigarettes, cigars, or pipes daily,

- Alcohol drinkers: who consume 1 alcoholic drink a day, a drink is 12 ounces of regular beer, 5 ounces of wine, or 1.5 ounces of 80 -proof distilled spirits. ${ }^{18}$

- Wealth quintiles were constructed by asking the presence or absence of durable assets and services at the household level. Categorical variables to be used are transformed into separate dichotomous $(0-1)$ indicators. These indicators and those that are continuous are then examined using a principal components analysis (PCA) to produce a common factor score. A separate indicator for urban and rural areas was produced and then giving a score of 1 if present and a score of 0 if absent. The asset mean scores were re-categorized into five different wealth Quintiles of equal proportion (Lowest, Second, Middle, Fourth, and Highest wealth control groups). Then after lowest and second recoded as poorest, poorer, middle richer and riches wealth class).

- Khat: is an illicit drug, which regular khat chewing causes gingivitis, tooth loss, gastric disorders, cardiac complications, male impotence, sleeplessness, and several mental health problems. ${ }^{19}$

\section{Data Analysis}

The collected data were cleaned and entered into EPI INFO 7 and exported to STATA version 12.1 for further analysis. Descriptive statistics and cross-tabulation were carried out, and the result was presented using text and tables. The Association of independent variables with breast cancer (outcome variable) was assessed with binary logistic regression and 95 Confidence Interval (CI) were computed to see the strength of association. Variables showing statistically 
significant association with the outcome variables up to a p-value of 0.2 were considered potential risk factors of breast cancer and were simultaneously subjected to a stepwise multiple logistic regression model to determine the significant independent risk factor of breast cancer. Variables were having less than 0.05 p-value in the final multivariable logistic regression analysis model considered as risk factors of breast cancer. The goodness of the model was assessed by Hosmer and lemeshow goodness fit test and was found to be a chi-square value of 9.36 with a corresponding p-value of 0.31 .

\section{Ethical Consideration and Consent to Participate}

Ethical clearance was obtained from the ethical clearance committee of the Institute of Public Health, University of Gondar. Permission to conduct the research was obtained from study hospitals. Informed consent is a requirement was obtained from the participants by explaining the study purpose, confidentiality issue, and their right to stop at any time during data collection. Those participants whose age below 18 consent was granted from their parents or caretakers. Regarding the ethical issues, this study protocol was conducted in accordance with the World Medical Association (WMA) Declaration of Helsinki.

\section{Result \\ Socio-Demographic Characteristics of Participants}

A total of 220 cases and control women aged above 15 years participated in the final study, with (97\% and $98 \%$ response rates for cases and controls, respectively. The mean (SD) of cases and controls were $43.8( \pm 12.63)$ and $39.6( \pm 12.91)$ years with statistically significant differences (P-value $=0.0165$ ) based on two groups' mean test. Moreover, 47(42.7\%) of cases and $62(56.4 \%)$ of controls aged between $20-40$ years, and $101(49.7 \%)$ of cases, and $102(50.3 \%)$ of controls were married. Regarding the level of education, about $66(61.8 \%)$ of

Table I Socio-Demographic Characteristics of Women of Age Above 15 Years in Addis Ababa City Hospitals, 2017 (N=220: Case $=110$ and Control $=110)$

\begin{tabular}{|c|c|c|c|c|}
\hline \multirow{2}{*}{ Variables } & \multirow{2}{*}{$\begin{array}{l}\text { Case, } \\
\mathbf{N}(\%)\end{array}$} & \multirow{2}{*}{$\begin{array}{l}\text { Control, } \\
\mathbf{N}(\%)\end{array}$} & \multirow{2}{*}{ Total, N (\%) } & \multirow[t]{2}{*}{ P-value } \\
\hline & & & & \\
\hline Age category in years & & & & 0.110 \\
\hline $15-40$ & $47(42.7 \%)$ & $62(56.4 \%)$ & $109(49.5 \%)$ & \\
\hline $40-49$ & $27(24.5 \%)$ & $27(24.5 \%)$ & $54(24.5 \%)$ & \\
\hline $50-59$ & $23(20.9 \%)$ & $13(11.8 \%)$ & $36(16.4 \%)$ & \\
\hline$>60$ & $13(11.9 \%)$ & $8(7.3 \%)$ & $21(9.6 \%)$ & \\
\hline Marital Status & & & & 0.801 \\
\hline Never Married & $9(52.9 \%)$ & $8(47.1 \%)$ & I7(7.7\%) & \\
\hline Married & $101(49.7 \%)$ & $102(50.3 \%)$ & $203(92.3 \%)$ & \\
\hline Level of education & & & & 0.179 \\
\hline Had no formal education & $24(21.8 \%)$ & $27(24.56 \%)$ & $5 \mathrm{I}(23.2 \%)$ & \\
\hline Primary education & $18(16.4 \%)$ & $26(23.6 \%)$ & $44(20 \%)$ & \\
\hline Secondary education & $44(40.0 \%)$ & $44(40.0 \%)$ & $88(40 \%)$ & \\
\hline Diploma and above & $24(21.8 \%)$ & $13(11.8 \%)$ & $37(16.8 \%)$ & \\
\hline Residence & & & & 1.00 \\
\hline Urban & $91(82.7 \%)$ & 94 (85.5\%) & $185(84.1 \%)$ & \\
\hline Rural & $19(17.3 \%)$ & $16(14.5 \%)$ & $33(15.9 \%)$ & \\
\hline Wealth Quintiles & & & & 0.153 \\
\hline Poorest & $13(1 \mid .8 \%)$ & $12(10.9 \%)$ & $25(11.4 \%)$ & \\
\hline Poorer & $32(29.1 \%)$ & $42(38.2 \%)$ & $74(33.6 \%)$ & \\
\hline Middle & $29(26.4 \%)$ & $34(30.9 \%)$ & $63(28.6 \%)$ & \\
\hline Richer & $27(24.5 \%)$ & $13(11.8 \%)$ & $40(18.2 \%)$ & \\
\hline Richest & $9(8.2 \%)$ & $9(8.2 \%)$ & $18(8.2 \%)$ & \\
\hline
\end{tabular}


cases, and 57(51.5\%) of controls had attended secondary and above level of education. The residence setting was dominated by urban residents $91(82.7 \%)$ for cases, and $94(85.5 \%)$ controls (Table 1).

\section{Behavioral Characteristics of Respondents}

About 7(7.6\%) of cases and 7(7.6\%) of controls ever chewed Khat and $41(37 \%)$ of cases and $35(31.8 \%)$ of controls experienced moderate stress in the past. In the majority of cases $80(72.7 \%$ ) and controls $85(77.3 \%$ ) drunk alcohol before and $78.2 \%$ of cases and $43.6 \%$ of controls were physically inactive. Regarding the dietary habit, about $45(40.9 \%)$ of cases and $40(36.4 \%)$ of controls consumed vegetables (Table 2).

\section{Reproductive and Family History Characteristics}

In this study, the majority of $100(90.9 \%)$ cases and 101 $(91.8 \%)$ controls reached their menarche after 12 years of age. Similarly, about 33(30\%) and controls $18(16.4 \%)$ had a history of abortion, likewise about $49(44.5 \%)$ of cases, and $25(22.7 \%)$ of controls were at menopausal age. Regarding oral contraceptive (OC) use, 67(60.9\%) of cases and $91(82.7 \%)$ of controls used oral contraceptives in their lifetime, and $14(12.3 \%)$ of cases and $8(7.3 \%)$ of controls had a family history of breast cancer (Table 3).

\section{Factors Associated with Breast Cancer}

From the binary logistic regression analysis, physical activity, menopausal status, breastfeeding, and body mass index

Table 2 Behavioral Characteristics of Women of Age Above 15 Years in Addis Ababa City Hospitals, 2017 (N=220: Case=II0 and Control= I 10)

\begin{tabular}{|c|c|c|c|c|}
\hline \multirow[t]{2}{*}{ Variables } & \multirow{2}{*}{$\begin{array}{l}\text { Case } \\
\text { Number (\%) }\end{array}$} & \multirow{2}{*}{$\begin{array}{l}\text { Control } \\
\text { Number (\%) }\end{array}$} & \multirow{2}{*}{$\begin{array}{l}\text { Total } \\
\text { Number (\%) }\end{array}$} & \multirow[t]{2}{*}{ P-value } \\
\hline & & & & \\
\hline Ever chew Khat & & & & 1.00 \\
\hline Yes & $7(6.4 \%)$ & $7(6.4 \%)$ & $14(12.7 \%)$ & \\
\hline No & $103(93.6 \%)$ & $103(93.6 \%)$ & $206(87.3 \%)$ & \\
\hline Ever passive smokers & & & & 0.178 \\
\hline Yes & $14(7.3 \%)$ & $8(1.8 \%)$ & $22(4.5 \%)$ & \\
\hline No & $96(92.7 \%)$ & $102(98.2 \%)$ & $198(95.5 \%)$ & \\
\hline Ever alcohol drinkers & & & & 0.436 \\
\hline Yes & $80(72.7 \%)$ & $85(77.3 \%)$ & $165(75 \%)$ & \\
\hline No & $30(27.3 \%)$ & $25(22.7 \%)$ & $55(25 \%)$ & \\
\hline Physical activity & & & & 0.0001 \\
\hline Low & $86(78.2 \%)$ & $48(43.6 \%)$ & $134(60.9 \%)$ & \\
\hline High & $24(21.8 \%)$ & $62(56.4 \%)$ & $86(39.1 \%)$ & \\
\hline Fruit intake & & & & 0.418 \\
\hline Yes & $22(20 \%)$ & $27(24.5 \%)$ & $49(22.3 \%)$ & \\
\hline No & $88(80 \%)$ & $83(75.5 \%)$ & $|7|(77.7 \%)$ & \\
\hline Vegetable intake & & & & 0.489 \\
\hline Yes & $45(40.9 \%)$ & $40(36.4 \%)$ & $85(38.6 \%)$ & \\
\hline No & $65(59.1 \%)$ & $70(63.6 \%)$ & $135(6 \mid .4 \%)$ & \\
\hline Stress & & & & 0.205 \\
\hline Low stress & $54(49.1 \%)$ & $66(60 \%)$ & $120(54.5 \%)$ & \\
\hline Moderate stress & $4 I(37.3 \%)$ & $35(31.8 \%)$ & $76(34.5 \%)$ & \\
\hline High stress & $15(13.6 \%)$ & $9(8.2 \%)$ & $24(11 \%)$ & \\
\hline BMI & & & & 0.0001 \\
\hline$<18.5 \mathrm{~kg} / \mathrm{m}^{2}$ & $13(1 \mid .8 \%)$ & $28(25.5 \%)$ & $4 I(18.6 \%)$ & \\
\hline $18.5-25 \mathrm{~kg} / \mathrm{m}^{2}$ & $50(45.5 \%)$ & $64(58.2 \%)$ & $1 \mid 4(51.8 \%)$ & \\
\hline$>25 \mathrm{~kg} / \mathrm{m}^{2}$ & $47(42.7 \%)$ & $18(16.3 \%)$ & $65(29.6 \%)$ & \\
\hline
\end{tabular}


Table 3 Reproductive and Family History Characteristics of Women of Age Above 15 Years in Addis Ababa City Hospitals, 2017 $(\mathrm{N}=220:$ Case $=110$ and Control=110)

\begin{tabular}{|c|c|c|c|c|}
\hline \multirow[t]{2}{*}{ Variables } & \multirow{2}{*}{$\begin{array}{l}\text { Case } \\
\text { Number (\%) }\end{array}$} & \multirow{2}{*}{$\begin{array}{l}\text { Control } \\
\text { Number (\%) }\end{array}$} & \multirow{2}{*}{$\begin{array}{l}\text { Total } \\
\text { Number (\%) }\end{array}$} & \multirow[t]{2}{*}{ P-value } \\
\hline & & & & \\
\hline Age at Menarche & & & & 0.810 \\
\hline$<12$ years & $10(9.1 \%)$ & $9(8.2 \%)$ & $19(8.6 \%)$ & \\
\hline$\geq 12$ years & $100(90.9 \%)$ & $101(91.8 \%)$ & $20 \mathrm{I}(9 \mathrm{I} .4 \%)$ & \\
\hline Parity & & & & 0.013 \\
\hline No & $26(23.6 \%)$ & $12(10.9 \%)$ & $38(17.3 \%)$ & \\
\hline Yes & $84(76.4 \%)$ & $98(89.1 \%)$ & $182(82.7 \%)$ & \\
\hline Abortion & & & & 0.017 \\
\hline No & $77(70 \%)$ & $92(83.6 \%)$ & $169(76.8 \%)$ & \\
\hline Yes & $33(30 \%)$ & $18(16.4 \%)$ & $5 \mathrm{I}(23.2 \%)$ & \\
\hline Menopausal status & & & & 0.001 \\
\hline Pre-menopause & $61(55.5 \%)$ & $85(77.3 \%)$ & $146(66.4 \%)$ & \\
\hline Menopause & $49(44.5 \%)$ & $25(22.7 \%)$ & $74(33.6 \%)$ & \\
\hline Ever breastfeeding & & & & 0.0001 \\
\hline Yes & $67(60.9 \%)$ & $97(88.1 \%)$ & $164(74.5 \%)$ & \\
\hline No & $43(39.1 \%)$ & $13(11.9 \%)$ & $56(25.5 \%)$ & \\
\hline Oral contraceptive use & & & & 0.0001 \\
\hline Yes & $67(60.9 \%)$ & $91(82.7 \%)$ & $158(7 \mid .8 \%)$ & \\
\hline No & $43(39.1 \%)$ & $19(17.3 \%)$ & $62(28.2 \%)$ & \\
\hline Family history & & & & 0.178 \\
\hline Yes & $14(12.7 \%)$ & $8(7.3 \%)$ & $22(10 \%)$ & \\
\hline No & $96(87.3 \%)$ & $102(92.7 \%)$ & $200(90 \%)$ & \\
\hline
\end{tabular}

(BMI) appeared to be associated with breast cancer at a 0.05 level of significance in the multivariable analysis after controlling the possible confounders. Hence, the odds of developing breast cancer among women who perform high physical activities decreased by $80 \%$ compared to those who practiced low physical activities $(\mathrm{AOR}=0.2,95 \% \mathrm{CI}$ : $0.10,0.41)$. Similarly, the odds of developing breast cancer among women who did not breastfeed had experienced were 3.4 times higher than those of women who had a history of breastfeeding ( $\mathrm{AOR}=3.4,95 \% \mathrm{CI}: 1.21,9.67)$. Likewise, the odds of developing breast cancer among menopause women were 6.8 times higher than pre-menopause women (AOR $=6.8,95 \%$ CI: $1.92,24.16$ ). Similarly, this study also revealed that the odds of developing breast cancer among women with a body mass index above $25 \mathrm{~kg} / \mathrm{m}^{2}$ had 5.9 times higher than those women with a body mass index less than $18.5 \mathrm{~kg} / \mathrm{m}^{2}$ (AOR=5.9, 95\% CI: 2.16, 16.48) (Table 4).

\section{Discussion}

Breast cancer women are the leading cause of morbidity and mortality among the non-communicable diseases identified in developing countries, including Ethiopia. The detection of risk factors for breast cancer is essential to the creation of prevention strategies of high public health significance. This research identified a range of risk factors that are appropriate for public health intervention. Physical exercise, breastfeeding, menopause, body mass index over $25 \mathrm{Kg} / \mathrm{m} 2$ risk factors for breast cancer have therefore been identified. In this study, a significant number of women under the age of 40 were screened for mammography used as a control in this study with a statistically significant age gap between case and control. In addition, the other factors may be due to family history of breast cancer, and some of the reasons for mammography screening at the earliest age of 40 years are suggested by physicians. In addition, the majority of women under 40 years of age had breast tenderness and discomfort associated with increased use of mammography screening. This was the limitation of the research and was recognized in the limitation portion of the study. As a result, women who performed high physical activity were associated with lower chances of breast cancer compared to those who 
Table 4 Factors Associated with Breast Cancer Using Logistic Regression Among Women Above I5 Years of Age in Addis Ababa, $2017(\mathrm{~N}=220$ : Cases=110 and Controls=110)

\begin{tabular}{|c|c|c|c|c|c|}
\hline \multirow[t]{2}{*}{ Explanatory Variables } & \multicolumn{2}{|c|}{ Breast Cancer } & \multirow[t]{2}{*}{$\operatorname{COR}(95 \% \mathrm{Cl})$} & \multirow[t]{2}{*}{$\operatorname{AOR}(95 \% \mathrm{Cl})$} & \multirow[t]{2}{*}{ P-value } \\
\hline & Cases & Control & & & \\
\hline \multicolumn{6}{|l|}{ Age categorized } \\
\hline$<40$ & 47 & 62 & 1 & I & \\
\hline $40-49$ & 27 & 27 & I.3(0.69-2.54) & $0.7(0.33-1.66)$ & 0.503 \\
\hline $50-59$ & 23 & 13 & $2.3(1.07-5.08)$ & $0.5(0.10-2.09)$ & 0.345 \\
\hline$\geq 60$ & 13 & 8 & $2.1(0.82-5.59)$ & $0.2(0.04-1.22)$ & 0.117 \\
\hline \multicolumn{6}{|l|}{ Physical activity } \\
\hline Low & 86 & 48 & 1 & $\mathrm{I}$ & \\
\hline Highest & 24 & 62 & $0.2(0.12-0.33)$ & $0.2(0.10-0.41)$ & 0.0001 \\
\hline \multicolumn{6}{|l|}{ Parity } \\
\hline No & 26 & 12 & 1 & 1 & \\
\hline Yes & 84 & 98 & $0.4(0.19-0.83)$ & $\mathrm{I}(0.28-3.80)$ & 0.943 \\
\hline \multicolumn{6}{|l|}{ Abortion } \\
\hline No & 77 & 92 & 1 & 1 & \\
\hline Yes & 33 & 18 & $2.2(1.14-4.19)$ & $2.1(0.90-4.94)$ & 0.067 \\
\hline \multicolumn{6}{|l|}{ Menopausal status } \\
\hline Pre-menopause & 61 & 85 & 1 & 1 & \\
\hline Menopause & 49 & 25 & $2.7(1.52-4.89)$ & $6.8(1.92-24.16)$ & 0.008 \\
\hline \multicolumn{6}{|l|}{ Ever breastfeeding } \\
\hline Yes & 67 & 96 & 1 & 1 & \\
\hline No & 43 & 13 & $4.8(2.39-9.58)$ & $3.4(1.21-9.67)$ & 0.022 \\
\hline \multicolumn{6}{|l|}{ Oral contraceptive use } \\
\hline Yes & 67 & 91 & I & I & \\
\hline No & 43 & 19 & $3.1(1.64-5.74)$ & $2(0.94-4.35)$ & 0.087 \\
\hline \multicolumn{6}{|l|}{ BMI } \\
\hline$<18.5 \mathrm{~kg} / \mathrm{m}^{2}$ & 13 & 28 & 1 & 1 & \\
\hline $18.5-25 \mathrm{~kg} / \mathrm{m}^{2}$ & 50 & 64 & I.7(0.79-3.58) & I.7(0.67-4.44) & 0.228 \\
\hline$>25.1 \mathrm{~kg} / \mathrm{m}^{2}$ & 47 & 18 & $5.6(2.39-13.20)$ & $5.9(2.16-16.48)$ & 0.001 \\
\hline
\end{tabular}

performed low physical activity. This finding was consistent with a study in Pakistan that documented a direct link between physical activity and breast cancer. ${ }^{6}$ This is because physical exercise helps regulate body weight, which helps to avoid the uncontrolled spread and growth of cells. In addition, physically active people are less likely to participate in other risk factors, such as drug use and high alcohol consumption. The American Cancer Society recommends that adults have at least 150 minutes of moderate-intensity or 75 minutes of vigorous-intensity exercise each week (or a combination of these) ideally distributed during the week. ${ }^{20-22}$

Conversely, this research found that no breast-feeding was associated with higher chances of breast cancer relative to breast-feeding. This result was consistent with the results of studies conducted in India, ${ }^{11}$ but this contradicts with the findings of the research in Brazil. ${ }^{23}$ This may be because breastfeeding is not common in developed countries compared to Ethiopia. In multiple epidemiological studies, breastfeeding has been identified as a protective factor against breast cancer. Researchers have shown that the potential mechanisms by which breastfeeding protects against breast cancer include: Reduced systemic estrogen and progesterone levels during lactation, excretion of estrogen and carcinogens from the breast ducts. ${ }^{24}$ Some others have an explanation for this potential impact may be due to breastfeeding, which decreases the total number of menstrual cycles of 
a woman's lifetime (the same as starting menstrual periods at a later age or going through early menopause).

Similarly, this research also found that overweight or those with BMI over $25 \mathrm{~kg} / \mathrm{m} 2$ correlated with an increased risk of breast cancer compared to those low BMI. This result was consistent with the previous systematic review and meta-analysis that found that $5 \mathrm{~kg} / \mathrm{m} 2$ was associated with a $2 \%$ increase in breast cancer risk. ${ }^{13,25-27}$ In addition, individuals with an elevated body mass index are correlated with sedentary patterns of increased risk factors for cancer.

This research also found that women of menopause age are more likely to have breast cancer than women of premenopausal age. This is also in line with other studies. ${ }^{28,29}$ However, this finding is in contrast with the Addis Ababa Cancer Registry report, which reported the highest incidence of breast cancer (38.4\%) among age groups 30-49 years of age. Most of the age group is in the premenopausal stage. However, this analysis has shortcomings First, it is not a national survey that only registers Addis Ababa people, and secondly, there are no specific pre-menopausal or post-menopausal status statistics that only deal with age groups. ${ }^{3}$

This research has implications for patients with breast cancer, cancer incidence, physicians, and policy makers for the identification of breast cancer determinants. Risk factors found in this study are of public health significance in the design of strategies to minimize the incidence of breast cancer among women. In addition, the factors described in this report, such as OC use, physical activity and breastfeeding practice, are modifiable risk factors that could be modified through health education and behavioral change activities.

\section{Strength and Limitation}

This research identified risk factors that physicians and public health experts may use to help them intervene and change risk factors. Breast cancer risk factors included BMI, breastfeeding, menopause, and physical activity, both of which could be changed with evidencebased treatments. The risk factors were studied in a case-control analysis with potential recall biases. Furthermore, since the participants were under the age of 40 , the study was exposed to control selection bias. Recall bias can influence some of the characteristics used, such as age at menarche, breastfeeding, vegetable intake, and level of physical activity. The study's limited sample size may have an effect on its strength and generalizability. This research also has drawbacks that were not tested, such as environmental pesticide (e.g., DDT) exposure, which was not included in the study due to the complexity of calculating it and the high cost of doing so.

\section{Abbreviations}

AFCRN, African Cancer Registry Network; AOR, Adjusted Odds Ratio; BMI, Body Mass Index; CI, confidence Interval; COR, Crude Odds Ratio; DDT, Dichloro-Diphenyl-Trichloroethane; LMIC, Low and Middle-Income Country; OC, Oral Contraceptive; SD, Standard Deviation; WHO, World Health Organization.

\section{Data Sharing Statement}

The data are available from the corresponding author upon reasonable request.

\section{Ethical Consideration and Consent to Participate}

Ethical clearance was obtained from the ethical clearance committee of the Institute of Public Health, University of Gondar. Permission to conduct the research was obtained from study hospitals. Informed consent is a requirement was obtained from the participants by explaining the study purpose, confidentiality issue, and their right to stop at any time during data collection. Those participants whose age below 18 consent was granted from their parents or caretakers. Regarding the ethical issues, this study protocol was conducted in accordance with the World Medical Association (WMA) Declaration of Helsinki.

\section{Acknowledgment}

We would like to thank the study participants, data collectors, supervisors and Addis Ababa city administration health bureau and selected hospital managers for their cooperation and support. Finally, we would like to thank all who directly or indirectly supported us.

\section{Author Contributions}

All authors contributed to data analysis, drafting or revising the article, have agreed on the journal to which the article will be submitted, gave final approval of the version to be published, and agree to be accountable for all aspects of the work. 


\section{Disclosure}

The authors declared that they have no competing interests.

\section{References}

1. The International Agency for Research on Cancer (IARC). 2018.

2. Bray F, Ferlay J, Soerjomataram I, Siegel RL, Torre LA, Jemal A. Global cancer statistics 2018: GLOBOCAN estimates of incidence and mortality worldwide for 36 cancers in 185 countries. CA Cancer J Clin. 2018;68(6):394-424. doi:10.3322/caac.21492

3. Network ACR. 2014.

4. Momenimovahed Z, Salehiniya H. Epidemiological characteristics of and risk factors for breast cancer in the world. Breast Cancer. 2019;11:151.

5. Abate S, Yilma Z, Assefa M, Tigeneh W. Trends of breast cancer in Ethiopia. Int J Cancer Res Mol Mech. 2016;2(1):1.

6. Bano R, Ismail M, Nadeem A, Khan MH, Rashid H. Potential risk factors for breast cancer in Pakistani women. Asian Pac J Cancer Prev. 2016;17(9):4309.

7. Bethea TN, Rosenberg L, Hong -C-C, et al. A case-control analysis of oral contraceptive use and breast cancer subtypes in the African American breast cancer epidemiology and risk consortium. Breast Cancer Res. 2015;17(1):1-13. doi:10.1186/s13058-015-0535-x

8. Ebrahimi M, Vahdaninia M, Montazeri A. Risk factors for breast cancer in Iran: a case-control study. Breast Cancer Res. 2002;4 (5):1-4. doi:10.1186/bcr454

9. Gueye M, Gueye SMK, Gueye MDN, et al. A hospital based case control study of female breast cancer risk factors in a Sub-Saharan African country. Int J Reprod Contracept Obstet Gynecol. 2016;5:7.

10. Ronco AL, Stefani ED, Deneo-Pellegrini H. Risk factors for premenopausal breast cancer: a case-control study in uruguay. Asian Pac J Cancer Prev. 2012;13:2879-2886.

11. Pakseresht S, Ingle GK, Bahadur AK, et al. Risk factors with breast cancer among women in Delhi. Indian J Cancer. 2009;46(2):132.

12. Nguyen J, Le QH, Duong BH, et al. A matched case-control study of risk factors for breast cancer risk in Vietnam. Int $J$ Breast Cancer. 2016;7.

13. Liu K, Zhang W, Dai Z, et al. Association between body mass index and breast cancer risk: evidence based on a dose-response metaanalysis. Cancer Manag Res. 2018;10:143. doi:10.2147/CMAR. S144619

14. Sj B, Mc L, Varma A, Nasca P, Weinstein A, Caplan AL. Breast cancer risk and alcohol consumption: results from a Large Case-Control Study. Int J Epidemiol. 1997;26:5. doi:10.1093/ije/ 26.5.915

15. Cohen S, Kamarck T, Mermelstein R. Perceived stress scale. Meas Stress. 1994;10:1-2.

16. Okobia M, Bunker C, Zmuda J, et al. Case-control study of risk factors for breast cancer in Nigerian women. Int J Cancer. 2006;119. doi:10.1002/ijc.22102
17. Hailemariam TT, Gebregiorgis YS, Gebremeskel BF, Haile TG, Spitznagle TM. Physical activity and associated factors among pregnant women in Ethiopia: facility-based cross-sectional study. $B M C$ Pregnancy Childbirth. 2020;20(1):92. doi:10.1186/s12884-020-2777-6

18. Getachew S, Lewis S, Britton J, Deressa W, Fogarty A. Prevalence and risk factors for initiating tobacco and alcohol consumption in adolescents living in urban and rural Ethiopia. Public Health. 2019;174:118-126. doi:10.1016/j.puhe.2019.05.029

19. Akalu TY, Baraki AG, Wolde HF, Lakew AM, Gonete KA. Factors affecting current khat chewing among male adults 15-59 years in Ethiopia, 2016: a multi-level analysis from Ethiopian demographic health survey. BMC Psychiatry. 2020;20(1):1-8. doi:10.1186/s12888020-2434-7

20. Mahoney MC, Bevers T, Linos E, Willett WC. Opportunities and strategies for breast cancer prevention through risk reduction. $C A$ Cancer J Clin. 2008;58(6):347-371. doi:10.3322/CA.2008.0016

21. Neilson HK, Farris MS, Stone CR, Vaska MM, Brenner DR, Friedenreich CM. Moderate-vigorous recreational physical activity and breast cancer risk, stratified by menopause status: a systematic review and meta-analysis. Menopause. 2017;24(3):322-344. doi:10. 1097/GME.0000000000000745

22. Lakshmi R, Athira R, Mary JT, Vijayalakshmi S. Breast cancer risk factors: preventable and non-preventable. Int Res J Pharm. 2012;3 (10):48-52.

23. Sergio BT, Elaine U, Cesar T. Breastfeeding and breast cancer: a case-control study in Southern Brazil. Cad SaúdePública. 2003;19 (6):1593-1601.

24. Lord SJ, Bernstein L, Johnson KA, et al. Breast cancer risk and hormone receptor status in older women by parity, age of first birth, and breastfeeding: a case-control study. Cancer Epidemiol Prev Biomarkers. 2008;17(7):1723-1730. doi:10.1158/1055-9965.EPI-07-2824

25. Babu KG, Anand A, Lakshmaiah KC, et al. Correlation of BMI with breast cancer subtype and tumour size. Ecancermedicalscience. 2018;12. doi:10.3332/ecancer.2018.845

26. Chen Y, Liu L, Zhou Q, et al. Body mass index had different effects on premenopausal and postmenopausal breast cancer risks: a dose-response meta-analysis with 3,318,796 subjects from 31 cohort studies. BMC Public Health. 2017;17(1):1-11. doi:10.1186/s12889017-4953-9

27. Ganju A, Suresh A, Stephens J, et al. Learning, life, and lactation: knowledge of breastfeeding's impact on breast cancer risk reduction and its influence on breastfeeding practices. Breastfeed Med. 2018;13 (10):651-656. doi:10.1089/bfm.2018.0170

28. Hosseinzadeh M, Ziaei JE, Mahdavi N, et al. Risk factors for breast cancer in iranian women: a Hospital-Based Case-Control Study in Tabriz, Iran. Breast Cancer. 2014;17(3):236.

29. Takalkar U, Asegaonkar S, Kodlikeri P, Kulkarni U, Borundiya V, Advani S. Hormone related risk factors and breast cancer: hospital Based Case Control Study from India. Res Endocrinol. 2014;6.

\section{Publish your work in this journal}

Breast Cancer - Targets and Therapy is an international, peer-reviewed open access journal focusing on breast cancer research, identification of therapeutic targets and the optimal use of preventative and integrated treatment interventions to achieve improved outcomes, enhanced survival and quality of life for the cancer patient.
The manuscript management system is completely online and includes a very quick and fair peer-review system, which is all easy to use. Visit http://www.dovepress.com/testimonials.php to read real quotes from published authors. 